\title{
Public Understanding of Science
}

http://pus.sagepub.com

\section{What's in a name? Commonalities and differences in public understanding of "climate change" and "global warming" \\ Lorraine Whitmarsh}

Public Understanding of Science 2009; 18; 401 originally published online Sep 16, 2008;

DOI: $10.1177 / 0963662506073088$

The online version of this article can be found at: http://pus.sagepub.com/cgi/content/abstract/18/4/401

\section{Published by: \\ (S) SAGE}

http://www.sagepublications.com

Additional services and information for Public Understanding of Science can be found at:

Email Alerts: http://pus.sagepub.com/cgi/alerts

Subscriptions: http://pus.sagepub.com/subscriptions

Reprints: http://www.sagepub.com/journalsReprints.nav

Permissions: http://www.sagepub.co.uk/journalsPermissions.nav

Citations http://pus.sagepub.com/cgi/content/refs/18/4/401 


\title{
What's in a name? Commonalities and differences in public understanding of "climate change" and "global warming"'
}

\author{
Lorraine Whitmarsh
}

This paper reports on findings from a survey of public understanding of climate change and global warming amongst residents in the south of England. Whereas much previous research has relied on survey checklists to measure public understanding of climate change, this study employed a more qualitative approach to reveal participants' unprompted conceptions of climate change and global warming. Overall, the findings show a tendency for the public to dissociate themselves from the causes, impacts, and responsibility for tackling climate change/global warming. This research gave particular attention to how terminology is understood by the public. The findings point to important qualitative, as well as quantitative, differences between public understanding of "climate change" and public understanding of "global warming." Furthermore, the latter term was found to evoke more concern than the former. As discussed in the article, these results have important implications for both researchers and communicators.

\section{Introduction}

There is increasing international acceptance that climate change is a serious threat to human wellbeing and environmental integrity (IPCC, 2007). Informing the public about the causes and impacts of climate change is widely regarded as a basic prerequisite for informed public decision-making and democratic participation. This recognition is embodied in Article 6 of the UNFCCC which highlights the value of "education, training, public awareness, public participation, public access to information and international cooperation" in ensuring all stakeholders are involved in the development and implementation of climate change policies.

In the UK, the Labour government has identified climate change as a priority issue, and positioned itself as a global leader in addressing it (e.g., HM Government, 2007). Public education to enlist societal support for and involvement in mitigation efforts is a key element of the UK government's climate change strategy. Since the early 1990s, there have been several government information campaigns intended to educate the UK public about climate change 
and to encourage personal energy conservation. Research into public knowledge of climate change suggests there has been some success from these public information campaigns, at least in terms of awareness levels. In England, only 1 percent of the public has not heard of "climate change," "global warming" or "the greenhouse effect" (DEFRA, 2002, 2007).

Furthermore, there is acceptance by most people in the UK (and, similarly, the USA) that climate change is a human-caused problem and a general awareness of the main causes and impacts. When prompted, most people can correctly identify destruction of forests, carbon emissions, emissions from transport, and emissions from power stations as contributors to climate change (BBC, 2004; Bostrom et al., 1994; Hinds et al., 2002). In England, the proportion able to identify the main causes of climate change has grown since 1993, suggesting awareness is increasing (DEFRA, 2002).

Yet, when respondents are not provided with a checklist of possible causes, their understanding is shown to be lower. In one MORI survey (Norton and Leaman, 2004), only 30 percent of Britons named carbon dioxide as the main gas contributing to climate change. Only 18 percent of respondents in a US survey mentioned burning fossil fuels, unprompted, as a cause (Read et al., 1994). Furthermore, qualitative studies in the USA indicate some confusion associated with climate change processes. Specifically, while quantitative research shows deforestation is widely recognized by the public as contributing to climate change, qualitative studies indicate that the role played by forests in sequestering carbon dioxide is poorly understood. Rather, many believe deforestation reduces oxygen production and the amount of "clean air" available (Bostrom et al., 1994; Kempton, 1991).

Similarly, findings relating to the public's understanding of the effects of climate change vary according to the methodology used. When shown a list of ecological and social problems (many of which scientists have not linked to climate change)-ranging from sea level rise to oxygen shortages and war-most respondents of a US survey considered they were possible effects of climate change (Read et al., 1994). Yet when asked, unprompted, what the effects of climate change will be, both US and UK publics most commonly identify changes in weather, including increased temperatures and rainfall (DEFRA, 2002; Dunlap, 1998; Hinds et al., 2002; Kempton, 1997; Lofstedt, 1996). Furthermore, qualitative studies of public understanding of climate change have shown that lay conceptions of the issue are often intimately tied to beliefs about social justice and environmental protection (e.g., Bulkeley, 2000; Darier and Schule, 1999).

These findings highlight two important points. Firstly, compared to checklist surveys, research that examines unprompted and contextual beliefs provides a more revealing insight into, and a more accurate reflection of, public understanding of climate change. Quantitative surveys can suffer from acquiescence bias, where respondents tend to agree with whatever options or statements are presented to them (Ray, 1990). Secondly, the public's interpretation of key concepts and terminology referred to in quantitative surveys should not be assumed to match expert definitions; qualitative research is necessary for exposing the various meanings associated with concepts like "climate change" and "deforestation." It is clear from previous studies, then, that quantitative and qualitative studies can elicit very different findings about public understanding of climate change. This implies a need for less Procrustean and more local, qualitative approaches to defining and researching public understanding and responses to climate change. Although some US research (e.g., Kempton, 1991) has used qualitative methods to address these issues, the extent to which these findings can be transposed to a UK context is not yet known.

This article reports findings from a study of public understanding of climate change in the south of England. This study was primarily exploratory, and aimed to reveal individuals' unprompted knowledge and beliefs about climate change. A key point of focus was on whether 
there is any variation in understanding according to the terminology used. Although the latest figures indicate that $99 \%$ of the public is now also familiar with the term "climate change", self-reported knowledge about "climate change" is still lower than about "global warming"; (DEFRA, 2007). Thus, a split-survey design compared responses to questionnaires using the term "climate change" with those using the term "global warming."

Since the 1980s, the term "global warming" has been commonly used to describe the impact on climate of increased levels of greenhouse gases linked to human activities. While the "warming" metaphor may have been effective in capturing the public's imagination about this global risk, it obscures the complex and potentially devastating range of effects resulting from what is more commonly referred to amongst scientists as the "enhanced greenhouse effect" or "climate change" (Houghton, 2004). The research described here explores whether the term "global warming" is more often associated with misperceptions than the term "climate change" is. Differences in affective and behavioral responses to these two terms are also examined.

Previous research indicates greater familiarity amongst UK and European publics with "global warming" than with "climate change." When shown the phrases "climate change," "global warming" and "the greenhouse effect," 99 percent of the English public say they have heard of at least one of these; yet the term "climate change" alone is only recognized by 78 percent (DEFRA, 2002). Similarly, two-thirds of the British public say they know "a great deal" or "a fair amount" about "global warming," compared to 59 percent who claim this level of knowledge about "climate change" (Norton and Leaman, 2004). However, while these surveys indicate different levels of awareness of "global warming" compared to "climate change," there has so far been virtually no attempt to examine whether these two terms are interpreted in qualitatively different ways. (There is one exception: Leiserowitz (2003) examined qualitative differences between the phrases in terms of affect as part of his unpublished doctoral dissertation.)

Clearly, the public's interpretation of these terms is significant for both researchers and communicators. Many surveys of public attitudes and knowledge about the issue have referred to "climate change" (Bibbings, 2004; DEFRA, 2002; Hargreaves et al., 2003; Poortinga and Pidgeon, 2003; Poortinga et al., 2006), while others use the term "global warming" (MORI, 2002; Norton and Leaman, 2004). In some cases, the two terms are combined in survey questions as "global warming/climate change" (MORI, 2005; Poortinga et al., 2006). Importantly, however, while the terminology used in these surveys varies, there is typically an implicit assumption that the two terms- "global warming" and "climate change"refer to the same thing (see, in particular, Lorenzoni et al., 2006). This is illustrated in a paper by Hargreaves et al. and a MORI report:

General lack of certainty about the causes of global warming is also reflected in the difficulty people have in connecting the local with the global, thereby understanding how the daily choices in their own lives might be linked to climate change. (Hargreaves et al., 2003: 37)

Whilst the majority (63\%) of Britons agree with Tony Blair that climate change is the most important environmental issue facing the world today, most see global warming as less serious than other issues. (Norton and Leaman, 2004: 5; see also MORI, 2005: 9)

The latter quote is from MORI's 2004 report The Day After Tomorrow: Public Opinion on Climate Change. Despite ostensibly describing public attitudes to "climate change," virtually all the survey questions in fact referred to "global warming."

Similarly, media coverage of the issue often uses the two terms indiscriminately or interchangeably (e.g., Henderson-Sellers, 1998), although the term "global warming" is most often preferred (Corbett and Durfee, 2004; Hargreaves et al., 2003). On the other hand, the 
term preferred by most scientists and the policy community is "climate change." This is evident not only from a brief (unscientific) review of academic journals but also from the titles of research and policy organizations in the field, e.g., the Intergovernmental Panel on Climate Change (IPCC), the UK's Tyndall Centre for Climate Change Research, and the Climate Change Research Center at the University of New Hampshire. Yet, communication from government and advisory groups equally conflates the two terms (e.g., RCEP, 2000; DEFRA, 2004). In their response to the government's proposed Climate Change Levy on businesses, the Energy Saving Trust (a UK non-profit organization, funded by government and the private sector, which campaigns for sustainable energy use and emissions reduction) states:

Climate change is the single biggest challenge facing the global community. Moreover there is a broad consensus amongst the world's scientists that global warming has already begun.... Climate change is caused by greenhouse gas emissions resulting from human activities. (EST, 1999: 1)

It is significant that even within the international policy community there is inconsistency in how the term "climate change" is used. The IPCC definition is "current or projected changes in climate whether due to natural variability or to human activities" (IPCC, 2001; my emphasis); whereas the UNFCCC defines it as: "climatic changes directly or indirectly resulting from human activities, over and above natural variation" (United Nations, 1992). Given this variation amongst decision-makers and communicators in the use and meaning of these terms, this would suggest that the public too are unlikely to have a clear understanding of key terminology.

The study described here sought to investigate both quantitative and qualitative commonality and variation amongst the UK public in their understanding of both "climate change" and "global warming." As indicated, this variation has important implications for effective communication and research on public understanding of climate change (or global warming).

\section{Methodology}

A postal questionnaire was developed using the findings from a series of semi-structured qualitative interviews with residents in the south of England. Details of the interviews are described in Whitmarsh (2005). The questionnaire comprised eight pages of quantitative and qualitative questions that addressed environmental concerns, awareness and knowledge of climate change and global warming, attitudes towards climate change and global warming, and behavior in relation to climate change and global warming. Although the time and effort for respondents to complete this would have been greater than for a conventional checklist questionnaire, this appears not to have adversely affected the survey response rate or representativeness (see below).

The questionnaire and survey methodology was piloted with around 20 people, including residents of sampled addresses. In total, 1771 questionnaires were distributed during September and October 2003 across six wards in Portsmouth (a city on the south coast of England) and the surrounding area using stratified random sampling. The selected wards represent a cross-section of socio-demographic groups.

In order to examine whether using different terminology ("global warming" or "climate change") affects the responses given, a split-sample survey design was employed, whereby half the sample was given a "climate change" questionnaire version, and the other half given a "global warming" version. (In all other respects the two questionnaire versions were identical.) The two questionnaire versions were distributed randomly across the sample, so that each sampled address had an equal chance of receiving a "climate change" or a "global warming" questionnaire. 
Of the 1771 postal questionnaires distributed, 589 were returned completed. This represents a total response rate of 33.3 percent, which is reasonable for an unsolicited postal survey (Oliver, 1990) and comparable to response rates for similar surveys (e.g., Black et al., 2001). Of the questionnaires returned, 277 (47 percent) were "climate change" questionnaires and 312 (53 percent) were "global warming" questionnaires. Comparison of the survey responses to recent census data for each ward indicates that in most respects the survey sample reflects the profile of the selected ward populations, with some notable differences. In particular, the survey sample is more educated than the total ward populations: 15 percent of the sample has no formal qualifications compared to 24 percent of the total population. A larger proportion of the survey sample ( 83 percent) than the total ward populations (72 percent) owns or regularly drives a car/van. Weighting the data to compensate for these differences produced very little change in the results. Therefore we can surmise that the under-representation of certain groups is not a biasing influence. The results discussed below are based on the unweighted data.

All questionnaire data were initially input into SPSS. The qualitative survey data were exported to NVivo and coded using a hierarchical coding procedure (Miles and Huberman, 1984). These qualitative data were used to explore themes in participants' understanding and meanings associated with key terminology. The qualitative data were also quantified to show the prevalence of conceptual themes, and to allow for comparative analysis. SPSS was used to produce descriptive and frequency statistics for all variables (including coded qualitative data), and to perform chi-square tests. These were used to determine whether there was any significant variation between responses using the two questionnaire versions.

\section{Results}

\section{Familiarity}

The survey initially determined whether respondents had heard of "climate change"/"global warming." As expected from previous surveys (DEFRA, 2002), only 2.9 percent of the total sample said they had not heard of climate change/global warming. However, choice of terminology is significant here. While 6.2 percent of respondents said they had not heard of "climate change," no respondents claimed not to have heard of "global warming" $(p<.001)$.

\section{Sources and trustworthiness of information}

The survey sought to investigate where people most commonly hear or learn about "climate change"/"global warming," and the degree to which "climate change"/"global warming" information is trusted. By far the most common sources of information selected by respondents were mass media-television (91.5 percent), newspapers (85.1 percent), and radio (65.7 percent). Despite being prolific, media information only inspires a moderate amount of trust (mean 2.7 on a 4-point scale; $1=$ not at all; $4=\mathrm{a}$ lot). The Internet (13.2 percent), libraries ( 7.1 percent) and journals (18.7 percent) are amongst the least popular sources of "climate change"/"global warming" information; however, consistent with previous studies (e.g., MORI, 2005), scientists are seen as the most trusted sources of information (mean score 3.5 out of 4 ).

Chi-square analysis of responses from questionnaires using different terminology indicates that sources of information about "global warming" were generally more popular than "climate change" information. For example, while 86.3 percent had heard about "climate change" from television, this proportion rises to 96.2 percent for "global warming" $(p<.001)$; similarly, 78.3 percent said they heard about "climate change" from newspapers, compared to 
91 percent who heard about "global warming" from this source $(p<.001)$. However, there is one notable exception to this trend: while 17.6 percent of respondents say they have heard of "global warming" from journals, this rises somewhat to 19.9 percent for "climate change." Although chi-square tests do not show this difference to be statistically significant, it is interesting nonetheless to speculate whether this may reflect the preference amongst scientists for the term "climate change."

Similarly, when respondents were asked about what they knew about "climate change"/"global warming," the "global warming" questionnaires evoked a higher proportion of responses overall. This is indicated by the column totals in Table 1. This suggests that respondents feel they know more about "global warming" than about "climate change."

This greater familiarity with global warming than with climate change is consistent with findings from DEFRA's (2002, 2007) and MORI's (Norton and Leaman, 2004) surveys. However, as I now discuss, this survey also found qualitative differences in participants' understanding of these two terms.

\section{Understanding}

Before examining understanding and attitudes about particular aspects of "climate change"/"global warming," the survey first elicited respondents' unprompted perceptions of the issue as a whole. Table 1 summarizes the most popular responses given to this open-ended question and where responses vary according to the terminology used in the questionnaire. After the initial open-ended question, the survey then asked respondents specifically about their knowledge of the impacts and causes, respectively, of "climate change"/"global warming." The results from these questions, including variation according to terminology, are shown in Tables 2 and 3.

We can see from Table 1 that, when respondents were asked what they knew about the issue, impacts of "climate change"/"global warming" were more commonly mentioned than any other aspects of the issue (e.g., causes, process, information source). Possible solutions to climate change/global warming were not mentioned at all. Of the causes mentioned, most relate to human activity. Yet while respondents cited more human than natural causes of "climate change"/"global warming" a notable 16.5 percent expressed doubt as to the reality or human causes of "climate change"/"global warming." Skepticism was a surprisingly common theme that emerged at the interview stage of the research (see Whitmarsh, 2005) and consequently was explored through attitude statements in the survey (see below). It is also significant to note the high proportion of respondents (17.1 percent) claiming to know little or nothing about "climate change"/"global warming."

\section{Understanding impacts}

The most commonly mentioned impact of "climate change"/"global warming" in response to the unprompted understanding question was temperature increase (23.6 percent of respondents), although this was significantly higher $(30.1$ percent; $p<.001)$ amongst respondents of "global warming" questionnaires. Change in weather/seasons (21.6 percent) was the next most popular response overall, and the most commonly mentioned impact amongst respondents of "climate change" questionnaires. Melting icebergs/glaciers, sea level rise, flooding, impacts on climate, drought/less rainfall, and increased rainfall were also mentioned.

When specifically asked what they thought the impacts of "climate change"/"global warming" are or will be (Table 2), survey respondents again more readily identified generic impacts that would potentially affect all life, rather than local or human-specific impacts. Over 6 out of 10 responses could be considered generic impacts, compared to 11 percent relating to other organisms specifically, and 19 percent to humans specifically. (There is a 
Table 1. Understanding of climate change and global warming as a whole (open-ended)

\begin{tabular}{|c|c|c|c|c|}
\hline \multirow{2}{*}{$\begin{array}{l}\text { Responses given to "What do } \\
\text { you know about } \\
\text { climate change/global } \\
\text { warming?" (open-ended) }\end{array}$} & \multirow{2}{*}{$\begin{array}{l}\% \text { of total survey } \\
\text { respondents* }\end{array}$} & \multicolumn{2}{|c|}{$\begin{array}{l}\% \text { of survey respondents by } \\
\text { questionnaire version* }\end{array}$} & \multirow[b]{2}{*}{ Sig. } \\
\hline & & Climate change & Global warming & \\
\hline Temperature increase $^{\mathrm{a}}$ & 23.6 & 16.2 & 30.1 & $p<.001$ \\
\hline Weather/seasons change ${ }^{\mathrm{a}}$ & 21.6 & 24.5 & 18.9 & n.s. \\
\hline Melting icebergs/glaciers ${ }^{\mathrm{a}}$ & 19.9 & 13.7 & 25.3 & $p<.001$ \\
\hline Ozone depletion/hole ${ }^{\mathrm{b}}$ & 19.9 & 13.7 & 25.3 & $p<.001$ \\
\hline Don't know much/anything ${ }^{c}$ & 17.1 & 19.1 & 15.4 & n.s. \\
\hline Doubt about reality/causes ${ }^{c}$ & 16.5 & 17.0 & 16.0 & n.s. \\
\hline Pollution $^{\mathrm{d}}$ & 11.9 & 6.9 & 16.3 & $p<.001$ \\
\hline Global impacts $^{\mathrm{a}}$ & 10.0 & 8.7 & 11.2 & n.s. \\
\hline Rising sea levels/land loss ${ }^{a}$ & 9.7 & 8.7 & 10.6 & n.s. \\
\hline Pollutants-other ${ }^{\mathrm{d}}$ & 9.2 & 3.2 & 14.4 & $p<.001$ \\
\hline Flooding ${ }^{\mathrm{a}}$ & 8.8 & 9.0 & 8.7 & n.s. \\
\hline Carbon dioxide ${ }^{\mathrm{d}}$ & 7.8 & 4.7 & 10.6 & $p<.01$ \\
\hline $\begin{array}{l}\text { UV penetrating/reduced } \\
\text { protection from sun }\end{array}$ & 7.6 & 2.2 & 12.5 & $p<.001$ \\
\hline Impacts on climate ${ }^{\mathrm{a}}$ & 6.5 & 8.7 & 4.5 & $p<.05$ \\
\hline Natural variation in climate ${ }^{\mathrm{d}}$ & 6.3 & 7.9 & 4.8 & n.s. \\
\hline Human caused (unspecified) ${ }^{\mathrm{d}}$ & 6.1 & 5.1 & 7.1 & n.s. \\
\hline Summers hotter, winters wetter ${ }^{\mathrm{a}}$ & 5.3 & 10.1 & 1.0 & $p<.001$ \\
\hline Impacts already observed $^{\mathrm{a}}$ & 5.3 & 7.2 & 3.5 & $p<.05$ \\
\hline Drought/less rainfall ${ }^{\mathrm{a}}$ & 5.3 & 7.6 & 3.2 & $p<.05$ \\
\hline Contradictory views/debate ${ }^{c}$ & 5.3 & 4.0 & 6.4 & n.s. \\
\hline Unsure/lack of knowledge ${ }^{c}$ & 5.1 & 4.0 & 6.1 & n.s. \\
\hline Greenhouse effect $^{\mathrm{b}}$ & 5.1 & 2.9 & 7.1 & $p<.05$ \\
\hline Media $^{\mathrm{e}}$ & 4.6 & 5.8 & 3.5 & n.s. \\
\hline $\begin{array}{l}\text { Trapping of heat/gases; } \\
\text { "blanket" analogy }\end{array}$ & 4.4 & 1.8 & 6.7 & $p<.01$ \\
\hline Deforestation $^{\mathrm{d}}$ & 4.2 & 4.0 & 4.5 & n.s. \\
\hline Natural causes-other ${ }^{\mathrm{d}}$ & 4.1 & 5.8 & 2.6 & $p<.05$ \\
\hline Greenhouse gases $^{\mathrm{d}}$ & 3.9 & 1.4 & 6.1 & $p<.01$ \\
\hline $\begin{array}{l}\text { 'Climate change' differentiated } \\
\text { from 'global warming'c }\end{array}$ & 3.9 & 5.1 & 2.9 & n.s. \\
\hline Cars/vehicle emissions $^{\mathrm{d}}$ & 3.7 & 2.2 & 5.1 & n.s. \\
\hline Increased rainfall $^{\mathrm{a}}$ & 3.7 & 5.4 & 2.2 & $p<.05$ \\
\hline Impacts_-all other ${ }^{\mathrm{a}}$ & 18.0 & 19.1 & 17.0 & n.s. \\
\hline Process-all other ${ }^{\mathrm{b}}$ & 10.0 & 7.6 & 12.2 & n.s. \\
\hline Causes_all other ${ }^{\mathrm{d}}$ & 9.2 & 5.1 & 12.8 & $p<.001$ \\
\hline Uncertainty-all other ${ }^{\mathrm{c}}$ & 7.5 & 5.8 & 9.0 & n.s. \\
\hline Total & 311 & 274.2 & 343.6 & \\
\hline
\end{tabular}

*Respondents typically gave several responses, so column totals are greater than $100 \%$.

Key: ${ }^{a}$ Impacts. ${ }^{b}$ Process. ${ }^{c}$ Uncertainty. ${ }^{d}$ Causes. ${ }^{e}$ Source of information. n.s., not significant.

distinction between percent of respondents versus percent of responses because the average number of coded responses given per respondent was 2.1.) Most commonly, respondents associated "climate change"/"global warming" with changes in weather (22.6 percent). Flooding and sea level rise were also commonly cited impacts. The most common humanspecific impacts mentioned were to agriculture/crops and health.

It is interesting to note that "temperature increase" was a much less common (7.8 percent) response when participants were asked specifically about impacts of "climate change"/"global warming" (Table 2) than for the earlier unprompted question (Table 1). As noted, respondents 
Table 2. Understanding of the impacts of climate change and global warming (open-ended)

\begin{tabular}{|c|c|c|c|c|}
\hline \multirow{2}{*}{$\begin{array}{l}\text { "What impacts, if any, do you think } \\
\text { climate change/global warming } \\
\text { may have?" (open-ended) } \\
\text { (categories of } 20 \text { responses } \\
\text { or fewer are excluded) }\end{array}$} & \multirow{2}{*}{$\begin{array}{l}\% \text { of total survey } \\
\text { respondents* }\end{array}$} & \multicolumn{2}{|c|}{$\begin{array}{l}\% \text { of survey respondents } \\
\text { by questionnaire version }\end{array}$} & \multirow[b]{2}{*}{ Sig. } \\
\hline & & Climate change & Global warming & \\
\hline Changes/extremes in weather ${ }^{\mathrm{a}}$ & 22.6 & 19.5 & 25.3 & n.s. \\
\hline Flooding ${ }^{\mathrm{a}}$ & 21.6 & 20.6 & 22.4 & n.s. \\
\hline Sea level rise/loss of land ${ }^{a}$ & 21.2 & 19.5 & 22.8 & n.s. \\
\hline $\begin{array}{l}\text { Impact on agriculture/food } \\
\text { supply }^{\mathrm{b}}\end{array}$ & 13.6 & 18.1 & 9.6 & $p<.01$ \\
\hline Melting ice caps/icebergs ${ }^{\mathrm{a}}$ & 10.9 & 7.2 & 14.1 & $p<.01$ \\
\hline Climatic impacts $^{\mathrm{a}}$ & 9.7 & 4.0 & 14.7 & $p<.001$ \\
\hline $\begin{array}{l}\text { Impacts on wildlife/ } \\
\text { vegetation/flora and fauna }^{\mathrm{c}}\end{array}$ & 8.8 & 10.5 & 7.4 & n.s. \\
\hline Human health/spread of disease ${ }^{b}$ & 8 & 8.3 & 7.7 & n.s. \\
\hline Temperature increase $/$ heat $^{\mathrm{a}}$ & 7.8 & 7.9 & 7.7 & n.s. \\
\hline Extinction of species ${ }^{c}$ & 7.3 & 7.2 & 7.4 & n.s. \\
\hline Drought/water shortages ${ }^{\mathrm{a}}$ & 7.1 & 7.2 & 7.1 & n.s. \\
\hline Catastrophe/destroy earth ${ }^{\mathrm{a}}$ & 4.9 & 4.0 & 5.8 & n.s. \\
\hline Long-term/future impacts ${ }^{\mathrm{a}}$ & 4.6 & 4.7 & 4.5 & n.s. \\
\hline $\begin{array}{l}\text { Uncertainty-unsure/lack } \\
\text { of knowledge }^{\mathrm{d}}\end{array}$ & 4.2 & 4.3 & 4.2 & n.s. \\
\hline General impacts-all other ${ }^{\mathrm{a}}$ & 18 & 16.2 & 19.6 & n.s. \\
\hline Human impacts-all other ${ }^{\mathrm{b}}$ & 14.4 & 15.9 & 13.1 & n.s. \\
\hline Non-human impacts - all other ${ }^{c}$ & 7.1 & 7.6 & 6.7 & n.s. \\
\hline Uncertainty—all other $^{\mathrm{d}}$ & 5.9 & 4.3 & 7.4 & n.s. \\
\hline
\end{tabular}

* Respondents typically gave several responses, so column totals are greater than $100 \%$.

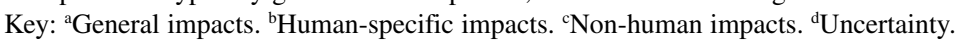

of "climate change" questionnaires were significantly less likely than respondents of "global warming" questionnaires to mention temperature increase for the unprompted question. However, there is no significant difference between questionnaire versions in the proportion mentioning temperature increase for the specific impacts question. This may indicate that temperature increase is equated with "global warming," but that it is not seen as an impact of "climate change"/"global warming" in the same way as are extremes of weather, flooding, sea level rise and so on.

\section{Understanding causes}

Of the causes of "climate change"/"global warming" mentioned, unprompted, by survey respondents (Table 1), by far the most common was pollution (11.9 percent). Survey respondents also mentioned, unprompted, a number of other anthropogenic causes, including carbon dioxide, deforestation, greenhouse gases and vehicle emissions. Natural variation in climate was cited by only 6.3 percent of respondents, and 4.1 percent mentioned other natural causes.

When asked specifically about the causes of "climate change"/"global warming" (Table 3) respondents similarly tended to cite human rather than natural causes. More than 4 in 5 responses relate to anthropogenic causes, compared to only 10 percent relating to natural causes. Again, the largest proportion of respondents (22.8 percent) cited pollution (in general) as a cause of "climate change"/"global warming." Particular sources of emissions or pollutants were also mentioned, including cars/traffic and industry/factories. A number of respondents 
Table 3. Understanding of the causes of climate change and global warming (open-ended)

\begin{tabular}{|c|c|c|c|c|}
\hline \multirow{2}{*}{$\begin{array}{l}\text { "What do you think causes climate } \\
\text { change/global warming?" } \\
\text { (open-ended) (categories with } 20 \text { or } \\
\text { fewer responses are excluded) }\end{array}$} & \multirow{2}{*}{$\begin{array}{l}\% \text { of total } \\
\text { survey } \\
\text { respondents* }\end{array}$} & \multicolumn{2}{|c|}{$\begin{array}{l}\% \text { of survey respondents } \\
\text { by questionnaire version }\end{array}$} & \multirow[b]{2}{*}{ Sig. } \\
\hline & & Climate change & Global warming & \\
\hline Pollution (general) ${ }^{\mathrm{a}}$ & 22.8 & 22.7 & 22.8 & n.s. \\
\hline Ozone layer depletion $^{\mathrm{a}}$ & 15.4 & 16.2 & 14.7 & n.s. \\
\hline Cars/traffic/exhaust fumes ${ }^{\mathrm{a}}$ & 11 & 6.5 & 15.1 & $p<.001$ \\
\hline $\begin{array}{l}\text { Natural—earth's cycles/weather } \\
\text { patterns }^{\text {b }}\end{array}$ & 10.5 & 12.3 & 9.0 & n.s. \\
\hline Industry/factory emissions ${ }^{\mathrm{a}}$ & 9.8 & 8.7 & 10.9 & n.s. \\
\hline Fossil fuel consumption/burning ${ }^{\mathrm{a}}$ & 9.2 & 6.5 & 11.5 & $p<.05$ \\
\hline Destruction of rainforest/trees ${ }^{\mathrm{a}}$ & 8.3 & 10.5 & 6.4 & n.s. \\
\hline Human activities (undefined) ${ }^{\mathrm{a}}$ & 7.6 & 7.2 & 8.0 & n.s. \\
\hline Carbon dioxide/carbon emissions ${ }^{\mathrm{a}}$ & 6.1 & 5.1 & 7.1 & n.s. \\
\hline $\mathrm{CFCs} / \mathrm{aerosols}{ }^{\mathrm{a}}$ & 4.4 & 2.2 & 6.4 & $p<.05$ \\
\hline $\begin{array}{l}\text { Emissions/fumes/waste gases } \\
{\text { (general })^{\mathrm{a}}}\end{array}$ & 4.2 & 3.6 & 4.8 & n.s. \\
\hline Chemicals $^{\mathrm{a}}$ & 4.1 & 3.6 & 4.5 & n.s. \\
\hline Description/explanation of process ${ }^{\mathrm{a}}$ & 3.9 & 2.5 & 5.1 & n.s. \\
\hline Greenhouse gases (undefined) ${ }^{\mathrm{a}}$ & 3.6 & 2.5 & 4.5 & n.s. \\
\hline $\begin{array}{l}\text { Blame of other people/organizations/ } \\
\text { countries (all other) })^{\mathrm{a}}\end{array}$ & 3.4 & 2.9 & 3.8 & n.s. \\
\hline $\begin{array}{l}\text { Moral dimension-overuse/misuse } \\
\text { of natural resources }{ }^{\mathrm{a}}\end{array}$ & 5.3 & 3.2 & 7.1 & $p<.05$ \\
\hline $\begin{array}{l}\text { Uncertainty-unsure/lack of } \\
\text { knowledge }^{c}\end{array}$ & 5.3 & 5.8 & 4.8 & n.s. \\
\hline $\begin{array}{l}\text { Confusion with impact/terminology } \\
\text { differentiated }^{\mathrm{c}}\end{array}$ & 4.4 & 6.5 & 2.6 & $p<.05$ \\
\hline Moral dimension-all other ${ }^{\mathrm{a}}$ & 15.8 & 18.4 & 13.5 & n.s. \\
\hline $\begin{array}{l}\text { Human activities-all other } \\
\text { activities }^{\mathrm{a}}\end{array}$ & 6.6 & 5.4 & 7.7 & n.s. \\
\hline $\begin{array}{l}\text { Uncertainty/ignorance-all } \\
\text { other }^{c}\end{array}$ & 6.5 & 6.5 & 6.4 & n.s. \\
\hline Natural—all other ${ }^{\mathrm{b}}$ & 6.1 & 7.2 & 5.1 & n.s. \\
\hline
\end{tabular}

*Respondents typically gave several responses, so column totals are greater than $100 \%$.

Key: ${ }^{\text {a} H u m a n ~ c a u s e s . ~}{ }^{\text {b Natural causes. }}{ }^{\text {CUncertainty. }}$

were aware of the connection between "climate change"/"global warming" and fossil fuel consumption, carbon emissions, (unspecified) greenhouse gases, and deforestation.

While understanding the contribution of air pollution and emissions to "climate change"/ "global warming" largely reflects expert views in relation to the role of emissions, there is divergence from expert conceptions in other senses. In particular, ozone depletion (19.9 percent) and (related to this) increased penetration of the sun's rays through the atmosphere (7.6 percent) were mentioned unprompted by respondents in their understanding of "climate change"/"global warming" (Table 1). Similarly, when asked specifically about their understanding of the causes of "climate change"/"global warming," ozone depletion was commonly mentioned (15.4 percent) and some respondents referred to chlorofluorocarbons (CFCs)/aerosols (4.4 percent) and chemicals (4.1 percent) (Table 3 ).

In contrast, only a small proportion of survey respondents (4.4 percent) referred to the trapping of heat or gases acting like a "blanket," or to the "greenhouse effect" (5.1 percent), in describing their understanding of "climate change"/"global warming" (Table 1). These reflect 
a more scientifically "accurate" understanding of the process of climate change. However, since the survey did not explicitly ask respondents about the mechanism through which climate change occurs, the proportion aware of these explanations may be greater.

Furthermore, these results show that respondents tend not to identify causes for "climate change"/"global warming" with their own actions, with only 0.5 percent mentioning domestic energy consumption as a cause.

Moreover, some responses (14 percent) to this question about the causes of "climate change"/"global warming" suggest a moral or normative dimension. Overuse or misuse of natural resources was mentioned by 5.3 percent of respondents (Table 3). Others talked about over-population, injustice, abuse of nature, the modern way-of-life, selfishness and greed. These moral concerns were also expressed by many interviewees (Whitmarsh, 2005).

As we can see from Tables 1, 2 and 3, the choice of terminology significantly affects how respondents understand the issue. The term "global warming" is more often associated with:

- heat-related impacts-in particular, temperature increase and melting icebergs and glaciers;

- human causes - including pollution, carbon dioxide and other greenhouse gases, CFCs, fossil fuel consumption, cars/traffic fumes, and overuse or misuse of earth's resources;

- ozone depletion and increased ultraviolet (UV) light penetration of the atmosphere;

- trapping of heat or gases within the atmosphere and the "greenhouse effect."

The term "climate change" is more readily associated with:

- a range of impacts on climate and the weather, including hotter summers, wetter winters, increased rainfall and drought, and impacts on agriculture/food supply;

- impacts that have already been observed;

- natural causes.

Indeed, there is evidence that some respondents understood "global warming" and "climate change" as different phenomena, with around 4 percent explicitly differentiating the two (Tables 1 and 3). Typically this was expressed as global warming causing climate change. For example, to the question "What do you know about climate change?" responses included:

Caused by global warming; the debate about whether climate change is induced by human activity i.e. global warming, CFCs, etc. or is a natural phenomena being part of a cycle based on past climatic conditions.

Climate change or global warming? If the latter, waste emissions and noxious fumes get trapped in earth's atmosphere and accumulate, preventing heat from dispersing and creating the so-called greenhouse effect.

Gradual change in average climate, probably brought about by global warming, hole in the ozone layer etc.

Pollution leading to ice cap melting leading to climate change.

We can see from these extracts that, while climate change and global warming are differentiated, they are closely linked to each other and to a range of other environmental phenomena, particularly ozone depletion.

\section{Attitudes, risk and concern}

The survey also measured attitudes to "climate change"/“global warming" using a battery of attitude statements. These statements were developed from previous qualitative interview data 
(Whitmarsh, 2005). Table 4 shows the total proportion of survey respondents selecting "agree" or "agree strongly" to each attitude statement, as well as the variation according to terminology in each case.

Overall, respondents most strongly agree that the government should provide incentives for pro-environmental action. Furthermore, the standard deviation for this statement $(0.73$; mean is 4.2 on 5-point scale) is the second lowest of all statements, indicating that there is less variation in the level of agreement. A number of other statements that attracted a high level of agreement relate to notions of responsibility, trust and social justice. Respondents agree that industry, business and government should do more to tackle "climate change"/"global warming." While they agree that everyone can "do their bit" to tackle "climate change"/"global warming," they also support the idea that the nature of human beings and modern society means that action should be equitably enforced, rather than left up to individuals.

Yet, despite a widespread tendency to place responsibility for tackling "climate change"/ "global warming" with industry and government, over half the sample (54.9 percent) agrees that individual activities (e.g., leaving the light on) contribute to "climate change"/"global warming." It seems most respondents acknowledge the role of domestic energy consumption in causing climate change once prompted, though very few identify it unprompted (see Tables 1 and 3). Similarly, although most respondents have little faith in other people to tackle "climate change"/"global warming," a majority (61.4 percent) claim to feel a moral obligation to do something about the issue, and very few (6.4 percent) feel there is no point in doing anything about it.

It is also noteworthy that around half the sample agrees that "The media is often too alarmist about issues like climate change/global warming," reflecting the ambivalent views on media trustworthiness noted earlier.

Chi-square analysis indicates that attitudes, like understanding, differ according to terminology. There was significantly higher agreement with "Global warming is inevitable because of the way modern society works" (59.4 percent) than with "Climate change is inevitable because of the way modern society works" (50.2 percent; $p<.01)$. Significantly more respondents agreed that "climate change," rather than "global warming," "is just a natural fluctuation in earth's temperatures" (27.9 percent, compared to 16 percent; $p<.01$ ). These differences relate to the finding, discussed above, that more respondents see "global warming" than "climate change" as a human-caused problem.

Furthermore, respondents appear to view "global warming" as a more serious, or at least more certain, issue than "climate change": for example, a higher proportion agreed that "It is too early to say whether climate change is really a problem" (27.8 percent) than agreed "It is too early to say whether global warming is really a problem" $(19.4$ percent; $p<.05)$.

The survey also addressed respondents' perceptions of "climate change"/“global warming" as a personal risk. When asked explicitly whether they are being, or will be, personally affected by "climate change"/"global warming," only 47.3 percent overall answered in the affirmative. No significant difference emerged according to terminology.

The survey addressed respondents' views about mitigation. When asked whether they believe anything can be done to tackle "climate change"/"global warming," 69.9 percent overall felt something could be done, with no significant variation according to terminology. When asked what could be done to tackle "climate change"/"global warming," the most popular response was "reducing pollution" or "reducing emissions" (18.7 percent). Results of the chi-square tests show a significantly higher proportion of "global warming" (7.1 percent) respondents mentioned individuals/the public could take action, compared to "climate 
Table 4. Attitudes to climate change and global warming (closed question)

\begin{tabular}{|c|c|c|c|c|}
\hline \multirow[b]{2}{*}{ Attitude statement* } & \multirow{2}{*}{$\begin{array}{c}\text { Total } \\
\text { agreement } \\
\text { (\% of total } \\
\text { sample) }\end{array}$} & \multicolumn{2}{|c|}{$\begin{array}{l}\% \text { of survey } \\
\text { respondents by } \\
\text { questionnaire } \\
\text { version }\end{array}$} & \multirow[b]{2}{*}{ Sig. } \\
\hline & & $\begin{array}{l}\text { Climate } \\
\text { change }\end{array}$ & $\begin{array}{c}\text { Global } \\
\text { warming }\end{array}$ & \\
\hline $\begin{array}{l}\text { The government should provide incentives for people to look after } \\
\text { the environment }\end{array}$ & 89 & 91.8 & 86.6 & n.s. \\
\hline Industry and business should be doing more to tackle climate change & 86.5 & 83.4 & 88.9 & n.s. \\
\hline We can all do our bit to reduce the effects of climate change & 83.3 & 83.0 & 83.6 & n.s. \\
\hline $\begin{array}{l}\text { People should be made to reduce their energy consumption if it reduces } \\
\text { climate change }\end{array}$ & 80.9 & 79.9 & 81.8 & n.s. \\
\hline If I come across information about climate change I will tend to look at it & 75.8 & 78.5 & 73.7 & n.s. \\
\hline Radical changes to society are needed to tackle climate change & 72 & 71.2 & 72.6 & n.s. \\
\hline Climate change is a consequence of modern life & 70.7 & 66.0 & 74.6 & n.s. \\
\hline People are too selfish to do anything about climate change & 68.9 & 69.9 & 68.1 & n.s. \\
\hline The government is not doing enough to tackle climate change & 68.5 & 68.0 & 68.9 & n.s. \\
\hline I feel a moral duty to do something about climate change & 61.4 & 62.5 & 60.6 & n.s. \\
\hline Experts are agreed that climate change is a real problem & 56.3 & 53.9 & 58.3 & n.s. \\
\hline Climate change is inevitable because of the way modern society works & 55.3 & 50.2 & 59.4 & $p<.01$ \\
\hline Leaving the lights on in my home adds to climate change & 54.9 & 56.5 & 53.6 & n.s. \\
\hline Pollution from industry is the main cause of climate change & 52.9 & 52.0 & 53.7 & n.s. \\
\hline The effects of climate change are likely to be catastrophic & 49.4 & 47.7 & 50.6 & n.s. \\
\hline The media is often too alarmist about issues like climate change & 49 & 52.2 & 46.5 & n.s. \\
\hline Recent floods in this country are due to climate change & 40.4 & 49.0 & 33.2 & $p<.001$ \\
\hline The United States should take most of the blame for climate change & 35.1 & 34.3 & 35.7 & n.s. \\
\hline $\begin{array}{l}\text { There is too much conflicting evidence about climate change to know } \\
\text { whether it is actually happening }\end{array}$ & 35.1 & 36.2 & 34.2 & n.s. \\
\hline $\begin{array}{l}\text { For the most part, the government honestly wants to reduce } \\
\text { climate change }\end{array}$ & 35 & 33.0 & 36.6 & n.s. \\
\hline Climate change is something that frightens me & 26.3 & 32.4 & 36.4 & n.s. \\
\hline The evidence for climate change is unreliable & 24.7 & 26.2 & 23.5 & n.s. \\
\hline It is too early to say whether climate change is really a problem & 23.3 & 27.8 & 19.4 & $p<.05$ \\
\hline Climate change is just a natural fluctuation in earth's temperatures & 21.3 & 27.9 & 16.0 & $p<.01$ \\
\hline $\begin{array}{l}\text { I would only do my bit to reduce climate change if everyone else } \\
\text { did as well }\end{array}$ & 19.7 & 19.9 & 19.6 & n.s. \\
\hline I am uncertain about whether climate change is really happening & 19.7 & 19.5 & 20.0 & n.s. \\
\hline Climate change will improve the British weather & 19.4 & 18.5 & 20.1 & $p<.01$ \\
\hline Developing countries should take most of the blame for climate change & 18.3 & 18.7 & 18.0 & $p<.05$ \\
\hline $\begin{array}{l}\text { Flooding is not increasing, there is just more reporting of it in the } \\
\text { media these days }\end{array}$ & 15.9 & 15.0 & 16.7 & n.s. \\
\hline Claims that human activities are changing the climate are exaggerated & 15 & 16.7 & 13.6 & n.s. \\
\hline Nothing I do on a daily basis contributes to the problem of climate change & 9.8 & 8.1 & 10.3 & n.s. \\
\hline I do not believe climate change is a real problem & 9.6 & 8.5 & 10.5 & n.s. \\
\hline Nothing I do makes any difference to climate change one way or another & 9.4 & 11.2 & 8.5 & n.s. \\
\hline I tend to consider information about climate change to be irrelevant to me & 7.9 & 7.4 & 8.4 & n.s. \\
\hline It is already too late to do anything about climate change & 7.5 & 7.7 & 7.3 & n.s. \\
\hline Human activities have no significant impact on global temperatures & 7.3 & 8.1 & 6.7 & n.s. \\
\hline $\begin{array}{l}\text { There is no point in me doing anything about climate change because } \\
\text { no-one else is }\end{array}$ & 6.4 & 7.7 & 5.4 & n.s. \\
\hline
\end{tabular}

*For brevity, the attitude statements in the table show only the "climate change" questionnaire version. 
Table 5. Ranked environmental concerns (checklist)

\begin{tabular}{lcccc}
\hline $\begin{array}{l}\text { "Please look at the following list of } \\
\text { environmental issues, }\end{array}$ & \multicolumn{3}{c}{ Questionnaire version } \\
$\begin{array}{l}\text { and circle the three issues } \\
\text { that concern you the most" }\end{array}$ & $\begin{array}{c}\text { \% of total survey } \\
\text { respondents }\end{array}$ & \begin{tabular}{c} 
Climate change \\
\cline { 3 - 5 }
\end{tabular} & Global warming & Sig. \\
\hline Traffic/congestion & 45.0 & 48.4 & 42.0 & n.s. \\
Water pollution & 31.1 & 32.5 & 29.8 & n.s. \\
Air pollution & 30.9 & 33.6 & 28.5 & n.s. \\
Poor waste management & 25.1 & 24.2 & 26.0 & n.s. \\
Resource depletion & 24.8 & 23.1 & 26.3 & n.s. \\
Litter & 24.3 & 27.4 & 21.5 & n.s. \\
Global warming/climate change & 19.9 & 16.2 & 23.1 & $p<.05$ \\
Extinction of species & 19.9 & 19.1 & 20.5 & n.s. \\
Overpopulation & 19.5 & 18.8 & 20.2 & n.s. \\
Flooding & 16.8 & 20.2 & 13.8 & $p<.05$ \\
Genetically modified food & 13.1 & 10.8 & 15.1 & n.s. \\
Radioactive waste & 11.4 & 9.4 & 13.1 & n.s. \\
Ozone hole & 10.5 & 12.6 & 8.7 & n.s. \\
\hline
\end{tabular}

change" respondents $(3.2$ percent; $p<.05)$. On the other hand, a significantly higher proportion of "climate change" respondents (6.5 percent) suggested stopping deforestation/planting trees, compared to "global warming" respondents ( 2.9 percent; $p<.05)$.

This research also examined concern about "climate change"/"global warming" relative to concern about other environmental issues (Table 5). Respondents were asked to select the three environmental issues that concerned them most from a list of 13 . Overall, we can see that concern about local environmental issues is generally higher than concern about global issues. The most popular environmental concern, selected by 45 percent of respondents, is "traffic/congestion," while "water pollution" (31.1 percent) and "air pollution" (30.9 percent) are also popular environmental concerns.

"Climate change"/"global warming" is ranked midway: 19.9 percent of respondents listed it as a concern. However, the wording of the questionnaire significantly influenced responses: the term "global warming" evoked concern amongst 23.1 percent of respondents, while "climate change" was only rated a concern for 16.2 percent $(p<.05)$. This reflects the greater seriousness ascribed to "global warming" than to "climate change" in the attitudinal section (Table 4).

Despite only a minority of survey respondents selecting "climate change"/“global warming" amongst their priority environmental concerns, most respondents (73.6 percent) consider the issue to be personally important (Table 6). Consistent with responses to the question on environmental concerns, a significantly higher proportion of respondents rate the issue as personally "very important" where the term "global warming" (28.5 percent) was used rather than "climate change" $(19.3$ percent; $p<.001)$. When asked why they feel the issue is of personal importance, "global warming" questionnaire respondents were significantly more likely to mention concern for family/future generations, environmental concern, impacts to environment or wildlife, and the future of the planet, compared to "climate change" questionnaire respondents (Table 7).

The survey also asked about personal behavioral response to "climate change"/"global warming," but no significant differences emerged according to terminology. Findings related to the prevalence and range of behavioral responses to "climate change"/"global warming" are discussed elsewhere (Whitmarsh, 2008b). 
Table 6. Personal importance of climate change/global warming issue (closed question)

\begin{tabular}{lccrr}
\hline $\begin{array}{l}\text { "How important is the } \\
\text { issue of climate change } \\
\text { to you personally?" }\end{array}$ & $\begin{array}{c}\text { \% of total } \\
\text { survey } \\
\text { respondents }\end{array}$ & Climate change & Global warming & Sig. \\
\cline { 3 - 4 } Not at all important & 4.3 & 8.0 & 1.0 & $p<.001$ \\
Not very important & 22.1 & 25.5 & 19.2 & $p<.001$ \\
Quite important & 49.4 & 47.3 & 51.3 & $p<.001$ \\
Very important & 24.2 & 19.3 & 28.5 & $p<.001$ \\
\hline
\end{tabular}

Table 7. Why is climate change/global warming an issue of personal importance to respondents?

\begin{tabular}{|c|c|c|c|c|}
\hline \multirow{2}{*}{$\begin{array}{l}\text { "Why is climate change } \\
\text { important to you?" }\end{array}$} & \multirow{2}{*}{$\begin{array}{c}\% \text { of total } \\
\text { survey respondents* }\end{array}$} & \multicolumn{2}{|c|}{ Questionnaire version } & \multirow[b]{2}{*}{ Sig. } \\
\hline & & Climate change & Global warming & \\
\hline $\begin{array}{l}\text { Motivation-responsibility/ } \\
\text { concern for family/ } \\
\text { future generations }\end{array}$ & 26.1 & 20.9 & 30.8 & $p<.01$ \\
\hline $\begin{array}{l}\text { Motivation-responsibility/ } \\
\text { concern for environment }\end{array}$ & 8.5 & 5.8 & 10.9 & $p<.001$ \\
\hline Impacts-weather, temperature & 7.0 & 5.8 & 8.0 & n.s. \\
\hline $\begin{array}{l}\text { Impacts-impacted, } \\
\text { changed environment }\end{array}$ & 6.6 & 3.6 & 9.3 & $p<.01$ \\
\hline $\begin{array}{l}\text { Impacts-moral dimension: } \\
\text { worldview/future of planet }\end{array}$ & 6.3 & 3.6 & 8.7 & $p<.05$ \\
\hline Impacts-impacts on wildlife & 6.1 & 4.0 & 8.0 & $p<.05$ \\
\hline Impacts-lifestyle/life & 4.4 & 4.3 & 4.5 & n.s. \\
\hline Impacts-health (general) & 4.1 & 4.7 & 3.5 & n.s. \\
\hline $\begin{array}{l}\text { Impacts-impacts on } \\
\text { humans/their survival }\end{array}$ & 4.1 & 2.9 & 5.1 & n.s. \\
\hline $\begin{array}{l}\text { Motivation-need and } \\
\text { possibility for action }\end{array}$ & 3.7 & 2.5 & 4.8 & n.s. \\
\hline Motivation-human-caused & 3.7 & 2.5 & 4.8 & n.s. \\
\hline Impacts_flooding & 3.6 & 5.1 & 2.2 & n.s. \\
\hline $\begin{array}{l}\text { Impacts_-moral dimension: } \\
\text { worldview/catastrophe/ } \\
\text { end of world }\end{array}$ & 3.6 & 3.2 & 3.8 & n.s. \\
\hline Impacts_-all other & 22.9 & 24.5 & 21.5 & n.s. \\
\hline Motivation-all other & 5.4 & 5.4 & 5.4 & n.s. \\
\hline
\end{tabular}

*Respondents sometimes gave more than one response, so column totals are greater than $100 \%$.

\section{Discussion}

\section{Defining public "understanding"}

As other studies have shown (e.g., DEFRA, 2002, 2007), awareness of the terms "climate change" and "global warming" is near universal. Broadly speaking, there is also recognition amongst respondents of the main causes and impacts of "climate change"/"global warming." However, while these survey findings largely reflect those of previous studies of public understanding of the causes of "climate change"/"global warming," this study shows a much lower proportion citing the main causes than in surveys that employed checklists. For example, UK government research (DEFRA, 2002) found that 74 percent of the public correctly identified "destruction of forests," 71 
percent "carbon dioxide emissions," 65 percent "emissions from transport," and 69 percent incorrectly identified "the hole in the ozone layer," when shown a list of possible climate change contributors. Hargreaves et al. (2003) report similar levels of agreement to their checklist question on causes of climate change. This compares to 8.3 percent identifying destruction of forests, 6.1 percent carbon dioxide, 11 percent vehicle emissions, and 15.4 percent ozone depletion, of respondents in the survey reported here, which did not provide a checklist of options. These proportions were generally lower again when respondents were asked, unprompted, about their understanding of the issue as a whole, rather than about causes specifically.

Furthermore, some findings from these previous checklist surveys are conspicuously absent from the responses given in this research. For example, in two different studies 10 percent of UK respondents (DEFRA, 2002), and 15 percent of Scottish respondents (Hinds et al., 2002), selected "use of mobile phones" as a contributor to climate change when shown a checklist of possible causes. Similarly, when presented with a list, the BBC (2004) found that as many as 13 percent of respondents identified "intensive farming." However, no respondents in the survey reported here mentioned mobile phones or intensive farming as causes of "climate change" or "global warming." These findings indicate checklist surveys suffer from acquiescence bias, whereby respondents tend to agree with whatever options or statements are presented to them (Ray, 1990). This reinforces the point that checklist surveys do not adequately measure "understanding," but rather reflect, at best, respondents' superficial recognition of abstract terms, and, at worst, their ability to "guess" and select several (both correct and incorrect) responses to hide their ignorance or uncertainty.

Indeed, this research has shown that, while recognition of the terms "climate change" and "global warming" is widespread, over one-fifth of respondents state they know little or nothing about the issue in question. As highlighted here and repeatedly in previous studies (e.g., Hargreaves et al., 2003; cf. BBC, 2004; Norton and Leaman, 2004; Bord et al., 2000), there continues to be an erroneous but prevalent conflation of "climate change"/"global warming" and ozone depletion. These findings would suggest a need amongst some sections of the public for basic education about the salient features of climate change/global warming.

On the other hand, the survey findings discussed here and the interview data discussed elsewhere (Whitmarsh, 2005) indicate that public understanding is not restricted to discrete "facts" about physical processes but is often integrated with other environmental issues (notably ozone depletion and air pollution) as part of a moral and cultural discourse involving issues of responsibility, trust and social justice. As discussed elsewhere (e.g., Wynne, 1991; Marshall, 1995), learning is a highly individualized process of relating novel and unfamiliar concepts to the familiar and understood, which results in inevitable variation in understanding about climate change/global warming-not only between non-experts and experts (Whitmarsh, 2004), but also amongst non-expert members of the public.

Thus, we can distinguish between "understanding" in the restrictive sense of knowledge (or recognition) of abstract scientific "facts"; and "understanding" in the fullest sense which includes how individuals apply scientific facts and principles to particular situations and express them in their understanding of the world. This distinction cuts to the core of the shift in focus away from the "information deficit model" towards more socially applied and contextual models of "dialogue" and "engagement" within research, science policy, and communication (e.g., LevyLeblond, 1992; Jackson et al., 2005).

\section{Public engagement}

Most respondents in this study feel "climate change"/"global warming" is important to them personally, although in relation to other environmental concerns climate change does not rank 
as high as more tangible and immediate threats to well-being, such as traffic or pollution. As previous studies have indicated (e.g., BBC, 2004; Norton and Leaman, 2004; Lorenzoni et al., 2006), climate change/global warming is not generally considered a direct personal risk. It is more often conceptualized as distant in space and time, with impacts affecting the wider environment and future generations. Similarly, this research and previous studies (DEFRA, 2002; Hargreaves et al., 2003; Kempton, 1991; Hinchliffe, 1996) show that the public tends not to associate causes with personal actions. Although most people in this study identify human activities in some way contributing to climate change/global warming-most commonly through pollution and ozone depletion-very few people readily associate it with their own energy use. Indeed, possible solutions or mitigation measures are not a feature of participants' conceptions of the issue, unless prompted. When explicitly asked about mitigation, responsibility for tackling climate change/global warming is most commonly placed with international organizations. These findings, and those of previous studies, indicate a tendency for the public to dissociate themselves from the causes, impacts, and responsibility for tackling climate change/global warming. Furthermore, the findings reported here point to unexpectedly widespread skepticism about the reality or human causes of climate change/global warming. This personal dissociation and skepticism has serious implications for effective climate change/global warming mitigation, which relies on acceptance by the public that climate change/global warming poses a risk to human well-being and recognition that their actions contribute to the problem (see Lorenzoni et al., 2007).

\section{Variation in understanding and responding to basic terminology}

While the findings from this research are broadly consistent with those from previous surveys of public understanding of climate change/global warming, examining beneath the overall picture, we see important differences in how key terms are understood.

The results show that awareness, affect and knowledge differ significantly according to terminology. Consistent with previous surveys (DEFRA, 2002, 2007 Norton and Leaman, 2004), in this survey respondents know more about "global warming" than about "climate change." More significantly, this research has shown that choice of terminology affects how the public understands and evaluates the issue. "Global warming" is more often believed to have human causes and tends to be associated with ozone depletion, the greenhouse effect and heat-related impacts, such as temperature increase and melting icebergs and glaciers. The term "climate change" is more readily associated with natural causes and a range of impacts. Furthermore, the term "global warming" evokes significantly more concern, and is rated as "very important" by more respondents, than the term "climate change." Finally, more people consider individual or public action to be an effective means of tackling "global warming" than do so for "climate change"; while a higher proportion believe planting trees could mitigate "climate change" than it could mitigate "global warming."

\section{Why might these differences arise?}

Firstly, source of information is significant. The variation in awareness by terminology may be a result of the media's tendency to refer to "global warming" instead of "climate change" (Corbett and Durfee, 2004), the latter being the term preferred by scientists and policy-makers. Given the public's reliance on media sources of information noted in this survey and elsewhere, this would explain the greater public familiarity with the term "global warming."

Also "global warming" may be a more emotive term, in part because it suggests a clear direction of change towards increasing temperatures; while the implications of "climate change" are more ambiguous. Furthermore, "global warming" may be seen as a more concerning and 
salient issue because of its currency in the mass media, which tends to dramatize and politicize science news (Hargreaves et al., 2003). By contrast, "climate change" is a more neutral termthere is no commitment implied as to the direction or cause of change. Indeed, this neutrality is demonstrated by the IPCC definition of climate change as "current or projected changes in climate whether due to natural variability or to human activities."

It may also be the case that the lower levels of public concern associated with the term "climate change" are due to its scientific connotations. Although not reported here, graduates and broadsheet readers who participated in this survey were found to be both more aware of scientific models of climate change and more skeptical that it is a human-caused problem; and science postgraduates were amongst the least likely to be concerned about climate change (see Whitmarsh, 2005). Furthermore, some interviewees felt that scientific evidence provides a more balanced and "rational" view of climate change by placing the issue in the context of natural climate fluctuations and the resilience of the environment (Whitmarsh, 2005). Other research has similarly noted that people who are ("irrationally") fearful of environmental problems can become less concerned and personally engaged as a result of exposure to non-emotional and scientific statements of "fact" (Finger, 1994; Henriksen and Jorde, 2001).

We should not go as far as to conclude that scientific conceptions necessarily undermine motivations to protect the environment. Nevertheless, this research does suggest uncertainty can be a product of knowledge rather than of ignorance. Previous research has similarly noted that attitudes towards science issues become more discriminating as knowledge increases (Evans and Durant, 1995; Bibbings, 2004). This knowledge paradox undermines the "deficit" model of science communication and poses a challenge to educators: for these skeptical groups, more information is not the solution to engaging them in the issue of climate change/global warming.

\section{Conclusions}

In this article I have argued for the need to distinguish genuine understanding of the causes and implications of climate change/global warming from superficial recognition of abstract terms used in survey checklists. The less restrictive survey design used in this research allowed participants to express their understanding in their own words and exposed the aspects of climate change/global warming that are uppermost in people's minds. This has called into question the findings of several previous surveys that indicate both widespread awareness of the main causes of climate change/global warming and a number of probable spurious misconceptions. The implications for future research into public understanding of scientific issues are that the limitations and biases inherent in quantitative surveys should be recognized, and greater use made of qualitative approaches to exploring understanding.

I have also pointed to a distinction between public understanding and engagement, and argued that there is a need for both. This research demonstrates firstly that there are significant sections of the public lacking even basic factual knowledge about climate change/global warming; and secondly low salience of climate change/global warming-both as a potential risk issue and as a consideration in energy use-in most people's day-to-day lives. The low levels of both understanding and engagement amongst the public in respect of climate change/global warming would indicate a need for more effective communication efforts. The findings from this research indicate that the media-while prolific-is not unproblematic as a source of public information. It is regarded by the public with varying levels of credibility and suffers from inherent constraints in its capacity to effectively communicate complex information to diverse audiences. It appears that individuals learn about climate change/global warming by relating it to their concerns, experiences and existing knowledge. As Newhouse (1990) explains, 
The learner must grasp how a topic is related to other things he or she values if the new information is to be integrated into the cognitive or affective domains in a manner sufficient to influence behavior. (p. 29)

One way to link climate change to individuals' lives may be to use air pollution as an appropriate springboard from which to initiate engagement with climate change/global warming messages. Firstly, this would build on the existing conceptual link between air pollution and climate change/global warming that is prevalent amongst the public. Secondly, highlighting the impacts on both climate and local air quality of personal actions, such as car use, would take advantage of widespread concerns about pollution. Weaving climate into discourses of pollution may bring the global environment closer to familiar cognitive and affective domains (see also Whitmarsh, 2008a).

Customized information is likely to have a greater impact on action. Tailored communication might include informational "feedback" on domestic energy use (Boardman and Darby, 2000). The rationale for this approach is that individuals are shown how particular actions contribute to their energy bills, and therefore can effectively modify their behavior to reduce their energy consumption. This information "makes visible what was previously invisible," namely energy use (Kempton et al., 1992: 1217). Furthermore, it highlights the financial benefits of action: positive messages tend to be more attractive and effective in motivating behavior change than negative ones (Burgess et al., 1998).

This research gave particular attention to the role that basic terminology played in public understanding. The findings point to important qualitative, as well as quantitative, differences between public understanding of "climate change" and public understanding of "global warming." These results have important implications for both researchers and communicators. Firstly, researchers must be aware that questionnaire wording will affect the responses given. As discussed earlier, there is no consistency between surveys in the questionnaire terminology used to research public knowledge or attitudes to climate change/global warming. More concerning, however, is the assumption in many reports of survey findings that the terms "climate change" and "global warming" are interchangeable (e.g., MORI, 2005). With research increasingly focusing on public response to this issue, there needs to be an explicit recognition that terminology is not neutral and should not be used indiscriminately. Secondly, communicators should be aware of the distinct connotations of "climate change" and "global warming" amongst audiences. Public information about "climate change" may evoke a different, perhaps lower, response than information referring to "global warming." On the other hand, "global warming" is more often associated with ozone depletion and heat-related impacts, and therefore may be misleading and reinforce widespread misperceptions. In this sense, then, there might be a trade-off between scientifically accurate communication and affective public engagement in climate change/global warming. Future research should investigate ways of overcoming this apparent trade-off. This could include explicitly highlighting where public conceptions are scientifically incorrect, before imparting accurate and engaging information (Kempton, 1997).

\section{Acknowledgements}

This paper is based on Ph.D. research funded by the University of Bath, UK. Grateful thanks go to David Gooding, Alan Lewis, Nick Pidgeon, Irene Lorenzoni and three anonymous reviewers for their valuable comments and advice; and to the interviewees and survey respondents who so kindly gave their time to make this research possible. 


\section{References}

BBC (2004) "Poll for Climate Change Special," URL (consulted January 2005): www.bbc.co.uk

Bibbings, J. (2004) Climate Concern: Attitudes to Climate Change and Windfarms in Wales. Cardiff: Welsh Consumer Council and Friends of the Earth Cymru.

Black, C., Collins, A. and Snell, M. (2001) "Encouraging Walking: the Case of Journey-to-School Trips in Compact Urban Areas," Urban Studies 38(7): 1121-41.

Boardman, B. and Darby, A. (2000) Effective Advice: Energy Efficiency and the Disadvantaged. Environmental Change Institute Research Report 24. Oxford: University of Oxford.

Bord, R.J., O'Connor, R.E. and Fisher, A. (2000) "In What Sense Does the Public Need to Understand Global Climate Change?," Public Understanding of Science 9: 205-18.

Bostrom, A., Morgan, M.G., Fischhoff, B. and Read, D. (1994) "What Do People Know about Global Climate Change? 1. Mental Models," Risk Analysis 14(6): 959-70.

Bulkeley, H. (2000) "Common Knowledge? Public Understanding of Climate Change in Newcastle, Australia," Public Understanding of Science 9: 313-33.

Burgess, J., Harrison, C. and Filius, P. (1998) "Environmental Communication and the Cultural Politics of Environmental Citizenship," Environment and Planning A 30: 1445-60.

Corbett, J.B. and Durfee, J.L. (2004) "Testing Public (Un)Certainty of Science: Media Representations of Global Warming," Science Communication 26(2): 129-51.

Darier, E. and Schule, R. (1999) “'Think Globally, Act Locally'? Climate Change and Public Participation in Manchester and Frankfurt," Local Environment 4(3): 317-29.

DEFRA (Department for Environment, Food, and Rural Affairs) (2002) Survey of Public Attitudes to Quality of Life and to the Environment-2001. London: DEFRA.

DEFRA (Department for Environment, Food, and Rural Affairs) (2004) Review of the UK Climate Change Programme: Consultation Paper. London: HMSO.

DEFRA (2007) Survey of Public Attitudes and Behaviors towards the Environment: 2007. London: DEFRA.

Dunlap, R. (1998) "Lay Perceptions of Global Risk: Public Views of Global Warming in Cross-National Context," International Sociology 13(4): 473-98.

EST (Energy Saving Trust) (1999) EST Briefing: The Case for the Climate Change Levy. London: Energy Saving Trust.

Evans, G. and Durant, J. (1995) "The Relationship between Knowledge and Attitudes in the Public Understanding of Science in Britain," Public Understanding of Science 4: 57-74.

Finger, M. (1994) "From Knowledge to Action: Exploring the Relationships between Environmental Experiences, Learning and Behavior," Journal of Social Issues 50(3): 141-60.

Hargreaves, I., Lewis, J. and Speers, T. (2003) Towards a Better Map: Science, the Public and the Media. London: Economic and Social Research Council.

Henderson-Sellers, A. (1998) "Climate Whispers: Media Communication about Climate Change," Climatic Change 40(3-4): 421-56.

Henriksen, E. and Jorde, D. (2001) 'High School Students' Understanding of Radiation and the Environment: Can Museums Play a Role?," Science Education 85(2): 189-206.

Hinchliffe, S. (1996) "Helping the Earth Begins at Home: the Social Construction of Socio-environmental Responsibilities," Global Environmental Change 6(1): 53-62.

Hinds, K., Carmichael, C. and Snowling, H. (2002) Public Attitudes to the Environment in Scotland 2002. Edinburgh: Scottish Executive.

HM Government (2007) Draft Climate Change Bill. Norwich: TSO.

Houghton, J., ed. (2004) Global Warming: The Complete Briefing, 3rd edn. Cambridge: Cambridge University Press.

IPCC (Intergovernmental Panel on Climate Change) (2001) Climate Change 2001: Impacts, Adaptation, and Vulnerability. Summary for Policymakers. Cambridge: Cambridge University Press.

IPCC (2007) The Physcial Science Basis. Summary for Policymakers. Contribution of Working Group I to the Fourth Assessment Report of the Intergovernmental Panel on Climate Change. Geneva: IPCC.

Jackson, R., Barbagallo, F. and Haste, H. (2005) "Strengths of Public Dialogue on Science-related Issues," Critical Review of International Social and Political Philosophy 8(3): 349-58.

Kempton, W. (1991) "Lay Perspectives on Global Climate Change," Global Environmental Change 1(3): 183-208.

Kempton, W. (1997) "How the Public Views Climate Change," Environment 39(9): 12-21.

Kempton, W., Darley, J.M. and Stern, P. (1992) "Psychological Research for the New Energy Problems," American Psychologist 47(10): 1213-23.

Leiserowitz, A. (2003) "Global Warming in the American Mind: The Roles of Affect, Imagery, and Worldviews in Risk Perception, Policy Preferences and Behavior," unpublished Ph.D. dissertation, University of Oregon. 
Levy-Leblond, J.-M. (1992) “About Misunderstandings about Misunderstandings,” Public Understanding of Science 1: $17-21$.

Lofstedt, R. (1996) “An Evaluation of a UK Energy Conservation Programme,” Energy and Environment 7(1): 41-9.

Lorenzoni, I., Leiserowitz, A., Doria, M., Poortinga, W. and Pidgeon, N. (2006) "Cross National Comparisons of Image Associations with 'Global Warming' and 'Climate Change' among Laypeople in the United States of America and Great Britain,” Journal of Risk Research 9(3): 265-81.

Lorenzoni, I., Nicholson-Cole, S. and Whitmarsh, L. (2007) "Barriers Perceived to Engaging with Climate Change among the UK Public and their Policy Implications," Global Environmental Change 17(3-4): 445-459.

Marshall, S. (1995) Schemas in Problem Solving. Cambridge: Cambridge University Press.

Miles, M.B. and Huberman, A.M. (1984) Qualitative Data Analysis: a Sourcebook of New Methods. London: SAGE Publications.

MORI (2002) “The Environment: Who Cares?,” URL (consulted January 2005): www.mori.com/environment

MORI (2005) Science in Society: Findings from Qualitative and Quantitative Research. London: MORI.

Newhouse, N. (1990) "Implications of Attitude and Behavior Research for Environmental Conservation," Journal of Environmental Education 22(1): 26-32.

Norton, A. and Leaman, J. (2004) The Day After Tomorrow: Public Opinion on Climate Change. London: MORI Social Research Institute.

Oliver, N. (1990) "Work Rewards, Work Values and Organisational Commitment in an Employee-owned Firm: Evidence from the UK," Human Relations 43: 513-26.

Poortinga, W. and Pidgeon, N.F. (2003) Public Perceptions of Risk, Science and Governance. Norwich: University of East Anglia/MORI.

Poortinga, W., Pidgeon, N. and Lorenzoni, I. (2006) Public Perceptions of Nuclear Power, Climate Change and Energy Options in Britain: Summary Findings of a Survey Conducted during October and November 2005. Understanding Risk Working Paper 06-02. Norwich: School of Environmental Sciences, University of East Anglia.

Ray, J.J. (1990) “Acquiescence and Problems with Forced-choice Scales," Journal of Social Psychology 130(3): 397-9.

RCEP (Royal Commission on Environmental Pollution) (2000) Energy: The Changing Climate. Twenty-second report. London: HMSO.

Read, D., Bostrom, A., Morgan, M.G., Fischhoff, B. and Smuts, T. (1994) "What Do People Know about Global Climate Change? 2. Survey Studies of Educated Laypeople," Risk Analysis 14(6): 971-82.

United Nations (1992) “United Nations Framework Agreement on Climate Change,” URL (consulted October 2006): http://unfccc.int/essential_background/convention/background/items/2853.php

Whitmarsh, L. (2004) "Communicating Climate Change: Challenges Posed by the Divergence in Lay and Expert Understanding," Paper presented at the Public Communication of Science and Technology Conference (PCST8), Barcelona, Spain, 3-6 June.

Whitmarsh, L. (2005) "A Study of Public Understanding of and Response to Climate Change in the South of England," unpublished doctoral thesis, Department of Psychology, University of Bath.

Whitmarsh, L. (in press) "Behavioural Response to Climate Change: Asymmetry of Intentions and Impacts. Journal of Environment Psychology, in press.

Whitmarsh, L. (2008a) Are Flood Victims More Concerned about Climate Change than Other People? The Role of Direct Experience in Risk Perception and Behavioural Response. Journal of Risk Research 11(3): 351-374.

Wynne, B. (1991) "Knowledges in Context," Science, Technology and Human Values 16(1): 111-21.

\section{Author}

Lorraine Whitmarsh is Senior Research Associate at the Tyndall Centre for Climate Change Research in the School of Environmental Sciences at the University of East Anglia, Norwich, UK. She completed her Ph.D., "A Study of Public Understanding of and Response to Climate Change in the South of England," in 2005 at the University of Bath. Since joining the Tyndall Centre, she has worked on the EU-funded MATISSE project researching processes of innovation and behaviour change in transitions to sustainability and developing participatory methods and modelling tools to support sustainability policy-making. She is currently researching carbon literacy, carbon offsetting and low-carbon lifestyles. She is a Visiting Fellow in the Psychology Department at the University of Bath. Correspondence: Tyndall Centre for Climate Change Research, School of Environmental Sciences, University of East Anglia, Norwich NR4 7TJ, UK; e-mail: 1.whitmarsh@uea.ac.uk 